\title{
Factors affecting the age of onset and rate of progression of Alzheimer's disease
}

\author{
John V Bowler, David G Munoz, Harold Merskey, Vladimir Hachinski
}

Department of Clinical Neurological Sciences J V Bowler

D G Munoz

V Hachinski

Department of Psychiatry H Merskey

Department of Pathology

D G Munoz

J P Robarts Research Institute, University of Western Ontario,

London, Ontario,

Canada

J V Bowler

D G Munoz

V Hachinski

Department of Clinical Neuroscience, Charing Cross and Westminster Medical School, University of London, London, UK

J V Bowler

Correspondence to: Dr JV Bowler, Memory Clinic, Department of Clinical Neuroscience, Charing Cross and Westminster Medical School, Fulham Palace Road, London W6 8RF, UK. Telephone 0044181846 7508; fax 0044181846 7715; email

j.bowler@cxwms.ac.uk

Received 8 September 1997 and in revised form 19 November 1997

Accepted 10 January 1998

\begin{abstract}
Objectives-To assess the role of cerebrovascular disease, sex, education, occupation, year of birth, leukoaraiosis, congophilic angiopathy, family history, and other demographic factors on the reported age of onset and rate of progression of Alzheimer's disease.

Methods-Analysis of data from the University of Western Ontario Dementia Study, a prospective longitudinal study of dementia patients with clinical and 6 monthly psychometric follow up to postmortem based in a university memory disorders clinic with secondary and tertiary referrals. There were 172 patients with dementia. The main outcome measures were the reported age of onset of cognitive decline as described by the family (available in 168) and rate of progression as measured during the linear phase of the extended scale for dementia, which could be calculated in 66 . The cases subdivided into 49 cases of definite Alzheimer's disease without infarcts, 25 cases of otherwise definite Alzheimer's disease with infarcts, 79 cases of probable Alzheimer's disease without infarcts, and 19 such cases with infarcts.
\end{abstract}

Results-The age of onset was not influenced by the rate of progression, the presence of cerebral infarcts, or congophilic angiopathy. Educational level, occupational level, sex, family history, year of birth, reported age of onset, severity at entry, an ischaemic score, and the presence of leukoariosis, affected neither age of onset nor the rate of progression. An earlier year of birth had a major effect and higher education had a minor effect on earlier age of onset. The earlier the year of birth, the lower the educational level and the greater the accrual of cerebral infarcts.

Conclusions-Contrary to series without pathological verification, age of onset in this study was not affected by occupation. Education had a modest effect on earlier reported onset, probably reflecting earlier recognition. As birth year has a strong effect on educational level and the occurrence of cerebral infarcts, this must be taken into account when analysing for risk factors for Alzheimer's disease. (f Neurol Neurosurg Psychiatry 1998;65:184-190)

Keywords: Alzheimer's disease; rate of progression; age of onset
Alzheimer's disease is the single commonest cause of dementia in the Occident affecting as many as $43 \%$ of 85 year old people. ${ }^{12}$ One of the most prominent debates recently has been the effect of education and occupation on the reported age of onset of Alzheimer's disease. Lower attainment is often associated with an increased risk of Alzheimer's disease ${ }^{3-10}$ although this was not confirmed in Framingham, ${ }^{11}$ Cambridge, ${ }^{12}$ Appignano, ${ }^{13}$ or Rochester. ${ }^{14}$ Many of these data come from epidemiological or population based studies. ${ }^{4-10}$ These use various cognitive assessments, some of which are very brief, and often base the diagnosis of dementia on rating scales without the involvement of a physician. The difficulties of using these reliably, because of the artefactual effect of education on cognitive rating scales, have been the subject of an extensive literature. ${ }^{12}{ }^{15-20}$ These studies are often without neuroimaging ${ }^{4-10}$ or follow up. ${ }^{4-6-10}$ Follow up is crucial to diagnostic accuracy in early Alzheimer's disease. ${ }^{21}$ Importantly, the Framingham study ${ }^{11}$ questioned the statistical methodology employed in many of these studies. It used longitudinal follow up, age adjustment, and classification of dementia by type and found that low educational level was not a risk factor; additionally, a cohort effect for educational attainment with year of birth was found. Age adjustment would therefore seem essential. ${ }^{11}{ }^{13}$ In addition, clinic based studies have found that increased education hastens the onset of Alzheimer's disease. ${ }^{22-24}$ Whereas the overall accumulated data make a case for a protective effect for education, leading to the "brain reserve" hypothesis, ${ }^{3}$ there are serious questions regarding the diagnoses and conclusions in these studies and appropriately analysed data based on pathologically established cases are needed.

A further very recent development has been the increasing recognition of mixed dementia and the suggestion of an intrinsic vascular ${ }^{25} 26$ or inflammatory component to Alzheimer's disease ${ }^{102526}$ based on the finding that nonsteroidal drugs may be protective against the disease. ${ }^{27-29}$ This could be due to more common arteriosclerosis in Alzheimer's disease which may be tied into the common finding of leukoaraiosis, ${ }^{25}$ a phenomenon not yet explained. Amyloid angiopathy, commonly seen in Alzheimer's disease, is not directly linked with this process. ${ }^{25}{ }^{26}$ To date there has been no estimate of the effect of these on the reported age of onset and rate of progression of Alzheimer's disease and hence no clear insight into their importance. 
The identification of factors affecting the reported age of onset and rate of progression of Alzheimer's disease has three other important implications. Firstly, for those factors that are modifiable, adverse factors might usefully be the subjects of clinical trials. Secondly, for those factors that are not modifiable, their inclusion as covariates in the analysis of clinical trials may increase the precision of the statistical tests and enhance the chances of detecting a treatment effect. Finally, the identification of unsuspected factors could lead to new hypotheses regarding the aetiology and pathogenesis of Alzheimer's disease.

The University of Western Ontario Dementia Study (UWODS) established that the rate of progression of moderate Alzheimer's disease is linear over the middle phase of decline in a postmortem established series ${ }^{30}$ when measured by the extended scale for dementia (ESD), ${ }^{31-33}$ a neuropsychological battery derived from the Mattis scale. This provides a valuable tool for assessing the effect of various factors on the rate of progression. We used these data to assess the effects of educational, occupational, and ischaemic aspects of Alzheimer's disease on its rate of progression and reported age of onset.

\section{Methods}

Data came from the UWODS. This is a prospective longitudinal study of Alzheimer's disease begun in 1977. It has both prolonged neuropsychological follow up of cases, with 6 monthly examination using the ESD, and extensive pathological confirmation. $\mathrm{VH}$ joined the study in 1982 and has personally seen and diagnosed all the cases in this report. The nature of the data collected for the study has evolved over the past 20 years and the cases reported here are those for which either the age at onset was recorded or the rate of progression could be calculated. There were 172 such cases. The age at onset was known in 166 and 66 had sufficient ESD follow up to calculate the rate of progression.

One hundred and five of these cases have died and postmortem information is available in $74(70 \%)$. We based the data analysis on this study on both definite and probable cases of Alzheimer's disease. For the purposes of this report, we gathered the accumulated clinical, radiological, and pathological data and reviewed the diagnoses to correspond with the following criteria.

Definite Alzheimer's disease was diagnosed if the histopathology matched CERAD criteria for Alzheimer's disease, ${ }^{34}{ }^{35}$ with no evidence of any other cause for the dementia, with the exception of infarcts. We reviewed all our histopathological data over the past two years to conform to the CERAD criteria. Microscopic cortical infarcts seen in association with amyloid angiopathy were not categorised as infarcts for the purposes of this analysis.

The clinical diagnosis of probable Alzheimer's disease always corresponded to standard criteria $^{3637}$ even though these formal criteria were published after the entry of some of these cases into the study. Brain CT or MRI was done in all cases along with basic haematology, biochemistry, syphilis serology, thyroid function, and serum B-12 and folate concentrations. Data from patients with active depression according to the hospital anxiety and depression scale ${ }^{38}$ or other causes of cognitive impairment were not used. Leukoaraiosis ${ }^{39}$ on CT or MRI, which is common in Alzheimer's disease $\mathrm{e}^{25}$ 40-42 did not exclude a diagnosis of the disease. We have shown that the positive predictive value of the initial clinical diagnoses of Alzheimer's disease is as low as $38 \%$ for pure Alzheimer's disease. ${ }^{21}$ To minimise the effect of this, we used prolonged follow up data taking progressive deterioration on the ESD as a surrogate marker for progressive dementia. ${ }^{21} 30$

Because the purpose of this study included the assessment of the effects of infarcts and leukoaraiosis on the rate of progression and reported age of onset of Alzheimer's disease, we admitted cases with infarcts found at postmortem or on neuroradiology among those reported here.

Information on education and occupation was collected from either the patient or the patient's carer. Education was rated on a four point scale $(1=$ no formal education (seven cases); 2 =failed to graduate from high school (70 cases); 3=graduated high school (49 cases); 4=university or college education (28 cases)). Data were missing in 18 cases. Occupation was scored on a three point scale with 1 being the highest. Homemakers were recorded as such in this database and not according to their partner's occupation. Because of the difficulty in ranking homemaker as an occupation, it was excluded from analysis resulting in missing data in 46 cases. A family history was defined as a history compatible with Alzheimer's disease in either, or both, of the subject's parents. Infarcts and leukoaraiosis were dichotomised as present or absent on both the radiological and pathological studies. Congophilic angiopathy was dichotomised as present or absent on the pathological material. Reported age of onset was established from the relatives during the clinical history. We used this, rather than age of first presentation, as reported age of onset was the primary variable of interest but it was closely correlated with age at presentation (analysis of variance (ANOVA) correlation coefficient $0.95, F$ ratio 1,474 , $\mathrm{p}<0.0001, \mathrm{R}^{2}=90 \%$ ) and reanalysis using age at presentation did not produce materially different results. Rate of progression was calculated using the linear phase of the ESD - that is, using only those scores between 50 and 200 . For subjects to have valid scores for rate of progression, at least three qualifying ESD observations were required and these had to span at least 1 year. The rate of change of ESD is expressed as units of ESD score per annum.

\section{Results}

From the 172 cases available for analyses, the criteria used to classify cases here produced 49 cases of pathologically confirmed definite Alzheimer's disease, 25 cases of otherwise definite Alzheimer's disease but with infarcts, 79 cases of clinically identified probable Alzheimer's disease 
Table 1 Factors affecting the rate of progression of Alzheimer's disease, with and without infarcts, for continuous and discrete variables and dichotomous variables

\begin{tabular}{|c|c|c|c|c|c|}
\hline Continuous and discrete variables & $n$ & Regression slope & \multicolumn{2}{|c|}{$\begin{array}{l}\text { ANOVA correlation } \\
\text { coefficient }\end{array}$} & $p$ Value \\
\hline Education $\dagger$ & 58 & \multirow{6}{*}{$\begin{array}{r}-0.315 \\
0.352\end{array}$} & & 0.322 \\
\hline Occupation $\dagger$ & 47 & & & & 0.820 \\
\hline Year of birth & 64 & & \multicolumn{2}{|c|}{-0.117} & 0.349 \\
\hline Age at onset & 58 & & \multicolumn{2}{|c|}{0.133} & 0.310 \\
\hline Initial ESD* & 66 & & \multicolumn{2}{|c|}{0.019} & 0.878 \\
\hline Ischaemic score ${ }^{\star}$ & 62 & & & & 0.535 \\
\hline & & Mean (SD) & & Mean $(S D)$ & \\
\hline Dichotomous variables & $n$ & Male & $n$ & Female & $p$ Value \\
\hline Sex & 27 & $-36.0(29.2)$ & 39 & $-27.1(17.8)$ & 0.130 \\
\hline Family history & 23 & $\begin{array}{l}\text { Present } \\
-26.7(23.8)\end{array}$ & 43 & $\begin{array}{l}\text { Absent } \\
-32.9(23.1)\end{array}$ & 0.306 \\
\hline Infarcts & 16 & $-35.6(29.6)$ & 50 & $-29.2(21.1)$ & 0.342 \\
\hline Infarcts (pathology) & 6 & $-28.0(12.2)$ & 20 & $-34.2(18.2)$ & 0.448 \\
\hline Infarcts (radiology) & 11 & $-39.0(34.7)$ & 52 & $-28.9(20.7)$ & 0.205 \\
\hline Leukoaraiosis (any) & 45 & $-30.6(26.5)$ & 21 & $-31.1(15.0)$ & 0.938 \\
\hline Leukoaraiosis (radiology) & 45 & $-30.6(26.5)$ & 18 & $-30.9(15.3)$ & 0.966 \\
\hline Leukoaraiosis (pathology) & 3 & $-30.7(6.1)$ & 23 & $-33.0(18.0)$ & 0.827 \\
\hline Congophilic angiopathy & 10 & $-28.6(12.3)$ & 16 & $-35.3(19.2)$ & 0.331 \\
\hline
\end{tabular}

^Spearman rank correlation. †Kruskal-Wallis. with necropsy ( $\mathrm{n}=69) 68.5$ (SD 8.6) years, without necropsy $(n=97) 67.3$ (SD 9.5), $\mathrm{p}=0.401)$.

None of the factors examined affected the rate of progression (table 1). Repeating these analyses for cases with pure Alzheimer's disease (those without any evidence of infarction whatsoever on imaging, necropsy, or both if applicable) and for those with evidence of mixed disease (evidence of infarction on one or both of neuroimaging and necropsy) also failed to disclose any factors affecting rate of progression.

The most powerful factor affecting the reported age of onset was year of birth (table 2 and figure). In the univariate analysis in the whole population, reported age of onset was highly significantly delayed in those with lower levels of education and occupation showed a trend in the same direction. The presence of infarcts, regardless of whether they were radiological, histological, or both, was associated with a reported age of onset 6 years later than those without infarcts. A similar trend was noted for a higher ischaemic score to be associated with a higher reported age of onset, and leukoaraiosis, when identified radiologically, was associated with a 3.6 year delay in reported age of onset. Increased severity at entry was associated with an older reported age of onset, although this effect was limited to those with infarcts. Rate of progression, sex, family history, and congophilic angiopathy were not associated with any change in reported age of onset.

Modelling for reported age of onset, excluding year of birth, using forward stepwise multiple regression showed that only infarcts (pathological or radiological) and educational level entered the model using $F$ to enter and $F$ to remove of 4. An ANOVA for this regression model showed that it was statistically highly significant ( $F$ ratio $12.5, \mathrm{p}<0.0001$ ) but that

Table 2 Factors affecting the reported age of onset of Alzheimer's disease, with or without infarcts, for continuous and discrete variables and dichotomous variables

\begin{tabular}{|c|c|c|c|c|c|}
\hline Continuous and discrete variables & $n$ & Regression slope & \multicolumn{2}{|c|}{ ANOVA correlation coefficient } & p Value \\
\hline Educationt & 148 & & \multirow{6}{*}{\multicolumn{2}{|c|}{$\begin{array}{r}-0.910 \\
0.133 \\
-0.179 \\
0.123\end{array}$}} & 0.001 \\
\hline Occupation $\dagger$ & 122 & & & & 0.110 \\
\hline Year of birth & 165 & -0.840 & & & $<0.001 ; \mathrm{R}^{2}=83 \%$ \\
\hline Rate of progression & 58 & 0.051 & & & 0.310 \\
\hline Initial $\mathrm{ESD}^{\star}$ & 163 & & & & 0.023 \\
\hline Ischaemic score ${ }^{\star}$ & 165 & & & & 0.116 \\
\hline Dichotomous variables & $n$ & $\begin{array}{l}\text { Mean (SD) } \\
\text { Male }\end{array}$ & $n$ & $\begin{array}{l}\text { Mean (SD) } \\
\text { Female }\end{array}$ & $p$ Value \\
\hline Sex & 67 & $66.9(9.7)$ & 70 & $68.4(8.7)$ & 0.287 \\
\hline Family history & 45 & $\begin{array}{l}\text { Present } \\
65.9(8.7)\end{array}$ & 118 & $\begin{array}{l}\text { Absent } \\
68.3(9.3)\end{array}$ & 0.135 \\
\hline Infarcts & 43 & $72.9(8.1)$ & 123 & $66.0(8.8)$ & $<0.001$ \\
\hline Infarcts (on histopathology) & 23 & $72.6(6.0)$ & 46 & $66.5(9.1)$ & 0.005 \\
\hline Infarcts (radiological) & 24 & $72.5(9.8)$ & 134 & $66.7(8.8)$ & 0.004 \\
\hline Leukoaraiosis (any) & 112 & $68.8(8.6)$ & 54 & $65.8(10.0)$ & 0.049 \\
\hline Leukoaraiosis (radiology) & 107 & $68.8(8.7)$ & 51 & $65.2(9.7)$ & 0.021 \\
\hline Leukoaraiosis (pathology) & 10 & $65.3(9.9)$ & 59 & $69.0(8.4)$ & 0.208 \\
\hline Congophilic angiopathy & 24 & $68.4(9.0)$ & 45 & $68.5(8.5)$ & 0.958 \\
\hline
\end{tabular}

^Spearman rank correlation.

†Kruskal-Wallis. 


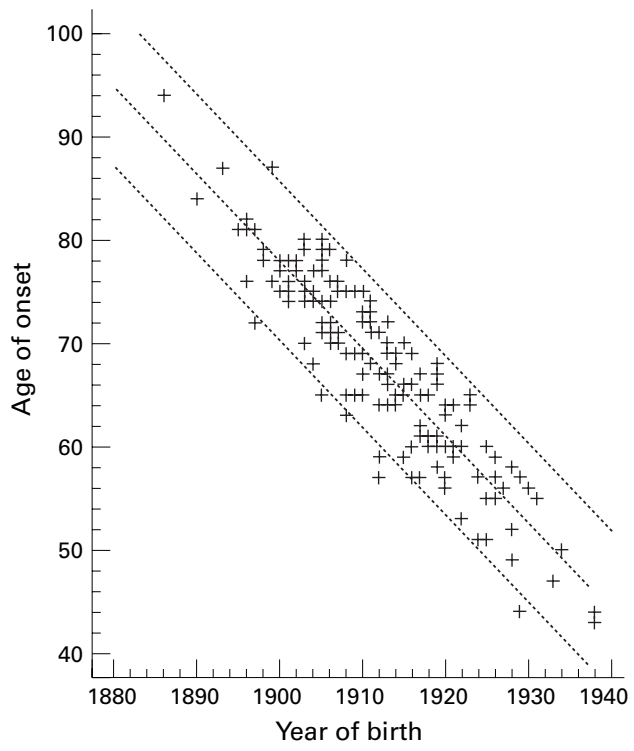

Reported age of onset is closely related to year of birth, partly because of a "sliding window" opportunity for entry into the study and partly because of cohort effects. the model accounted for relatively little of the variance $\left(R^{2}=15.3 \%\right)$. Inclusion of year of birth resulted in only year of birth and educational level entering the model. An analysis for this regression model showed that it was statistically highly significant $(F$ ratio 370 , $\mathrm{p}<0.00001)$ and the model now accounted for most of the variance $\left(\mathrm{R}^{2}=84 \%\right)$. The residual effect of education was now small at -0.93 (years per unit of education), $\mathrm{p}=0.013,95 \%$ confidence interval $(95 \% \mathrm{CI})-1.7$ to -0.2 .

In pure Alzheimer's disease (cases without any evidence of infarction, radiological or on necropsy) a low educational level was still associated with a later reported age of onset in the univariate analysis (table 3). In this subgroup, leukoaraiosis detected at necropsy, but not when seen only radiologically, was also associated with an earlier reported age of onset. However, year of birth was still the most significantly associated and only year of birth and educational level entered the model ( $F$ to remove 155 and 5; ANOVA $F$ ratio 85, $\mathrm{p}<0.00001, \mathrm{R}^{2}=81 \%$ ).

Table 3 Factors affecting the reported age of onset of pure Alzheimer's disease (no coexistent cerebrovascular disease), for continuous and discrete variables and dichotomous variables

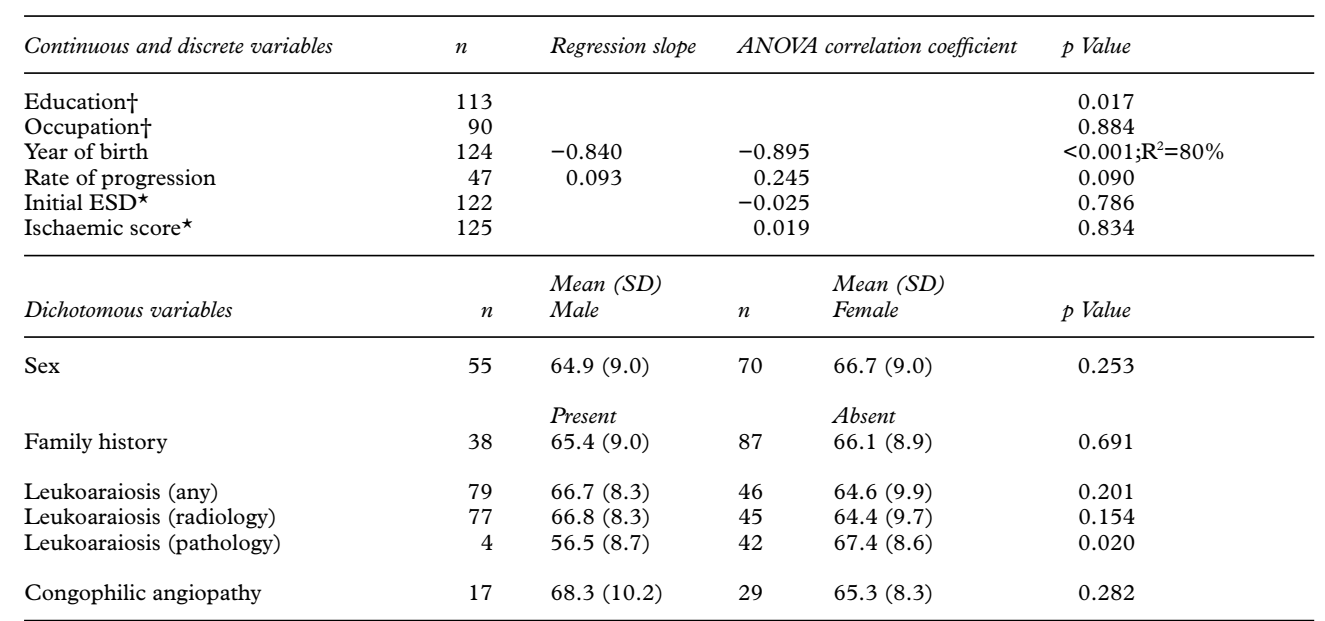

^Spearman rank correlation. †Kruskal-Wallis.

Table 4 Factors affecting the reported age of onset of Alzheimer's disease with infarcts, for continuous and discrete variables and dichotomous variables

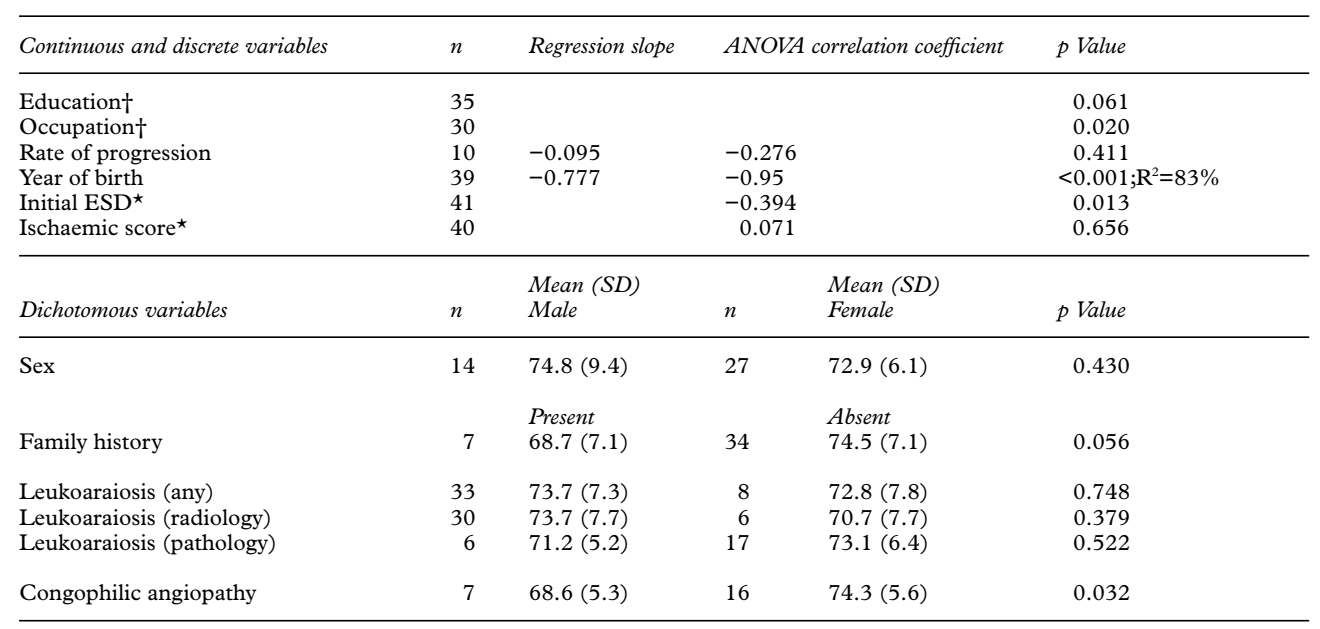

*Spearman rank correlation.

†Kruskal-Wallis. 
In mixed disease (both Alzheimer's disease and evidence of infarction) the effect of educational level disappeared although weak evidence for an association between low occupational level and a delayed onset of dementia appeared (table 4). Increased severity at entry was very weakly associated with a later reported age of onset. Weak evidence, based on small numbers, was found for an earlier reported age of onset in those with congophilic angiopathy. Only year of birth entered the model (ANOVA $F$ ratio $155, \mathrm{p}<0.00001, \mathrm{R}^{2}=84 \%$ ).

Further analysis of year of birth showed that educational levels increased from 2.2 to 3.2 on the four point scale over the range of the subjects' years of birth (1886 to 1938) (ANOVA $F$ ratio $11, \mathrm{p}=0.0013$ ). Occupational level also increased, but did not reach significance. Similarly, infarcts were more common in those born earlier. For those with evidence of infarction, the mean year of birth was 1906 (SD 9), $\mathrm{n}=44$, compared with 1914 (SD 10), $\mathrm{n}=128$ for those without, $\mathrm{p}=0.000003$, confirming that accrual of infarcts with increasing age could explain the apparent protective effect of infarcts.

Ninety eight of the patients have died. Factors affecting age of onset had broadly similar effects on the age at death. This was higher in those with lower levels of education (level $1(\mathrm{n}=5)$ mean age $=87.6(\mathrm{SD} 2.2)$; level 2 $(\mathrm{n}=46) 79.8$ (SD 8.7); level $3(\mathrm{n}=31) 75.2$ (SD $7.3)$; level $4(\mathrm{n}=16) 78.4$ (SD 7.6) (KruskalWallis $\mathrm{p}=0.0016)$ ). Occupation acted in the same way but did not reach significance. Again, the presence of infarcts was associated with an apparent protective effect in that the age of death was 5.3 years later in those with infarcts. However, there was again a powerful association between year of birth and age at death (regression slope -0.9 (SE 0.03), p<0.00001, $\left.\mathrm{R}^{2}=91 \%\right)$ and inclusion of this in stepwise multiple regression excluded education and infarcts from the model.

\section{Discussion}

Seventy four (43\%) of our cases were histologically established. For the remainder, the positive predictive value of a diagnosis of Alzheimer's disease in this database was over $80 \%$ and the incorporation of evidence of progression in those cases where it was available and radiological data into the diagnostic algorithm should increase this figure. ${ }^{21}{ }^{43}$ Thus it is very likely that over $90 \%$ of our non-necropsied cases had a correct diagnosis.

Few reports ${ }^{44}$ on the rate of progression of Alzheimer's disease used serial administration of quantified neuropsychological tests rather than softer outcome variables such as admission to a nursing home or death, ${ }^{46}{ }^{47}$ which are subject to interference by other matters such as domestic circumstances. None of the factors that we examined significantly affected the rate of progression as measured during the linear phase of decline of Alzheimer's disease. ${ }^{304}$ Using the linear phase excludes ceiling and floor effects, which both occur with the ESD, and so these cannot be the explanation for the absence of any effects on the rate of progres- sion. An alternative explanation is that the factors that we have analysed do affect the rate of progression, but at earlier or later stages of the disease such that we excluded the relevant data. Although we cannot exclude this possibility, we know of no other evidence to support it. The relatively few subjects in whom a rate of progression could be calculated, along with the large SD, raises the risk of a type II error in some of our findings. In particular, the lack of effect of infarcts on rate of progression is surprising. For a two tailed test $\beta=39 \%$; as a one tailed test predicting that infarcts accelerate the decline, $\beta=28 \%$ so we cannot make a negative conclusion about the effect of infarcts based on our data. The lack of effect of congophilic angiopathy $(\beta=42 \%)$ is also at risk of type II error but the conclusions on the lack of difference between the sexes are more secure $(\beta=13 \%)$ despite the difference in the means. For the other results, the differences in the means, or the correlation coefficients, are too small to make an important type II error likely. Sex, age at onset, severity at entry, family history, and duration of illness did not affect the rate of progression in previous work ${ }^{44} 4549-54$ although positive findings exist for family history, ${ }^{55355}$ age (with contradictory results), ${ }^{56-58}$ and severity. ${ }^{59}$ We conclude that Alzheimer's disease progresses remorselessly, regardless of education, occupation, and the other factors tested although we cannot make a firm negative conclusion about the effect of coexistent cerebrovascular disease and congophilic angiopathy.

The most powerful factor affecting reported age of onset was year of birth. This association has several components. We have confirmed a cohort effect for both education ${ }^{1122}{ }^{23}$ and coexistent cerebrovascular disease. Correction by age at entry to the study would be sufficient to deal with this in a cross sectional study. However, because UWODS recruited patients over many years, age at the time of study, as adjusted for in the Framingham study, ${ }^{11}$ is not a sufficient correction. For example, a patient recruited aged 70 in 1978 would have been born in 1908 but the same patient recruited towards the end of the study in 1991 would have been born in 1921. Thus correction by year of birth, rather than age at time of study, is required. However, we have also identified a previously unrecognised major artefact; UWODS was referral based, as are most memory clinics, and referral is usually made only once, typically shortly after recognition of symptoms. For a patient born in 1900 to have entered UWODS he would have to have been in his late 70s; conversely, a patient born in 1940 could have been no older than 51 . This means that a "sliding window of opportunity" exists for subjects to enter clinic based studies that does not exist in cross sectional population based studies. Thus a later year of birth, and hence greater educational opportunity, better health care etc are all associated with a younger reported age of onset for a second entirely artefactual reason in a clinic population. Cohort effects are compounded by the "sliding window of opportunity." This almost completely 
explains the dilemma of increasing education being associated with an earlier reported age of onset in memory clinic based studies and largely explains the paradox in this kind of study that increasing educational attainment is associated with lower reported age of onset. It does not, however, fully account for the effect as increasing education was still associated with an earlier presentation of Alzheimer's disease after adjustment for year of birth but the residual effect is very small.

We were initially suspicious that this residual effect was an artefact of case recognition. Relatives of patients with higher levels of ability, who themselves are likely to be more able, may notice subtle changes earlier than might otherwise be the case and, through better access to physicians, may also be assessed and referred more quickly. However, the very close correlation between reported age of onset and age of referral makes it unlikely that the speed of referral was a major factor, suggesting that it is recognition by relatives that is more important. A comparison of the first ESD score on entry to the study did not support this suggestion either as this did not differ significantly between those with low and high education (low education ESD at entry 103 (SD 83); high education 119 (SD 86), $\mathrm{p}=0.23$ ). Thus, whereas we could not prove the existence of an artefact of case recognition, we also could not disprove one as the study was not designed to do this.

An alternative explanation would be that coexistent cerebrovascular disease might cause Alzheimer's disease to appear at an earlier age. However, coexistent cerebrovascular disease would be expected to be more common in those with lower educational and occupational attainment and so would act in the opposite sense to our findings. This possibility is conclusively eliminated by the identification of the same effect for education in the cases with no evidence at all of cerebrovascular disease, and the elimination of the effect of education in those with coexistent cerebrovascular disease. Having not been able to confirm either of the artefactual explanations, or a role for cerebrovascular disease, we remain uncertain as to the reason but speculate that an artefact of case recognition is the explanation.

These findings provide evidence against the "use it or lose it" hypothesis. This hypothesis proposes that higher educational and occupational levels have a protective effect against Alzheimer's disease. Three mechanisms may mediate this. One is the establishment of a cognitive reserve, perhaps as more synapses or more efficient synapses, such that more have to be lost before the disease is manifest, so delaying onset. The second is that increased intellectual activity may enhance brain repair and recovery mechanisms, so slowing the rate of progression. Finally, other brain regions may take over the functions of those affected early in the disease and some functional evidence exists for this hypothesis. ${ }^{606}$ Our inability to identify any effect of education or occupation on rate of progression is contrary to the predictions of the second component whereas the earlier re- ported age of onset in those with higher education is contrary to the predictions of the first component.

Although infarcts were the second most powerful factor affecting the reported age of onset in the univariate analysis, delaying it by 6 years, this did not retain significance in the multivariate analysis after inclusion of year of birth. Further analysis shows that this is because the cases with infarcts were born, on average, 7 years earlier than those without. These cases will therefore have entered the study when they were 7 years older than those without infarcts by virtue of the sliding window phenomenon. This almost exactly matches the apparent protective effect of infarcts and discloses the univariate effect to be an artefact of study design.

This study provides evidence against the view, based on community surveys, that higher education and occupation delay the onset of Alzheimer's disease. We found very little evidence that demographic variables have any real influence on the reported age of onset, rate of progression, or age at death of patients with Alzheimer's disease. The effect that increased education had was to cause the earlier presentation of Alzheimer's disease, although this was a weak effect in the multivariate analysis. We have also shown, using quantitative histopathology in the same population, that there is no evidence for the histopathological correlates that would be expected if the brain reserve hypothesis was true (del Ser T, Hachinski VC, Munoz DG, unpublished observations).

Community based studies are not at risk of the "sliding window" artefact but are at risk of other problems. Many of these, such as the lack of imaging and the reliance on short cognitive tests, possibly biased against those with lower education despite statistical correction, are well recognised. Others are less well recognised. Depression in elderly people is more common in those with lower educational and occupational attainment ${ }^{62} 63$ and depression is a powerful mimic of early dementia. This will act to cause overrepresentation of apparent dementia among the less educated. Mortality from all causes is lower in those with higher levels of education. In a community based study, this selective mortality will cause those of lower educational attainment to die early so depriving them of the opportunity to dement in later old age. This may also cause the artefactual early onset of Alzheimer's disease in the less well educated.

We conclude that neither the reported age of onset nor the rate of progression of Alzheimer's disease, with or without coexisting cerebrovascular disease, are influenced by education or occupation and that claims to the contrary, in either direction, have arisen because of imperfect methodology and unrecognised sources of error.

JVB was a fellow with the Heart and Stroke Foundation of Ontario. Funding for this analysis was provided by the Ministry of Health of Ontario Trillium Clinical Scientist Award to VH. 
1 Ebly EM, Parhad IM, Hogan DB, et al. Prevalence and types of dementia in the very old: results from the Canadian Study of Health and Aging. Neurology 1994;44:1593-600

Skoog I, Nilsson L, Palmertz B, et al. A population-based study of dementia in 85-year-olds. N Engl F Med 1993;328: 153-8.

3 Katzman R. Education and the prevalence of dementia and Alzheimer's disease. Neurology 1993;43:13-20.

4 Stern Y, Gurland B, Tatemichi TK, et al. Influence of education and occupation on the incidence of Alzheimer's disease. FAMA 1994;271:1004-10.

5 Ott A, Breteler MM, van Harskamp F, et al. Prevalence of Alzheimer's disease and vascular dementia: association with education. The Rotterdam study. BMF 1995;310:9703.

6 Rocca WA, Bonaiuto S, Lippi A, et al. Prevalence of clinically diagnosed Alzheimer's disease and other dementing disorders: a door-to-door survey in Appignano, ing disorders: a door-to-door survey in Appigna

7 Sulkava R, Wikstrom J, Aromaa A, et al. Prevalence of severe dementia in Finland. Neurology 1985;35:1025-9.

8 Callahan CM, Hall KS, Hui SL, et al. Relationship of age, education, and occupation with dementia among a community-based sample of African Americans. Arch Neu rol 1996;53:134-40.

9 Zhang MY, Katzman R, Salmon D, et al. The prevalence of dementia and Alzheimer's disease in Shanghai, China: impact of age, gender, and education. Ann Neurol 1990;27: 428-37.

10 Anonymous. The Canadian study of health and aging: risk factors for Alzheimer's disease in Canada. Neurology 1994; 44:2073-80.

11 Cobb JL, Wolf PA, Au R, et al. The effect of education on the incidence of dementia and Alzheimer's disease in the Framingham study. Neurology 1995;45:1707-12.

12 O'Connor DW, Pollitt PA, Treasure FP. The influence of education and social class on the diagnosis of dementia in a
community population. Psychol Med 1991;21:219-24.

13 Bonaiuto S, Rocca WA, Lippi A, et al. Education and occupation as risk factors for dementia: a population-based pation as risk factors for dementia: a population-b

14 Beard CM, Kokmen E, Offord KP, et al. Lack of association between Alzheimer's disease and education, occupation, marital status, or living arrangement. Neurology 1992;42: 2063-8.

15 O'Connor DW, Pollitt PA, Treasure FP, et al. The influence of education, social class and sex on mini-mental state scores. Psychol Med 1989;19:771-6.

16 Jorm AF, Scott R, Henderson AS, et al. Educational level differences on the mini-mental state: the role of test bias. Psychol Med 1988;18:727-31.

17 Fillenbaum GG, Hughes DC, Heyman A, et al. Relationship of health and demographic characteristics to mini-mental state examination score among community residents. Psychol Med 1988;18:719-26.

18 Escobar JI, Burnam A, Karno M, et al. Use of the mini-mental state examination (MMSE) in a community population of mixed ethnicity. Cultural and linguistic artipopulation of mixed ethnicity. Cultural and

19 O'Connor DW, Pollitt PA, Hyde JB, et al. The reliability and validity of the mini-mental state in a British community validity of the mini-mental state in a
survey. F Psychiatr Res 1989;23:87-96.

20 O'Connor DW, Pollitt PA, Hyde JB, et al. The prevalence of dementia as measured by the Cambridge mental disorders of the elderly examination. Acta Psychiatr Scand 1989;79: $190-8$

21 Bowler JV, Munoz DG, Merskey H, et al. Fallacies in the pathological confirmation of the diagnosis of Alzheimer's disease. F Neurol Neurosurg Psychiatry 1998;64:18-24.

22 Moritz DJ, Petitti DB. Association of education with reported age of onset and severity of Alzheimer's disease at presentation: implications for the use of clinical samples. Am f Epidemiol 1993;137:456-62.

23 Peterson B. Association of education with reported age of onset and severity of Alzheimer's disease at presentation: implications for the use of clinical samples. Am f Epidemiol implications for

24 Duara R, Barker WW, Lopez-Alberola R, et al. Alzheimer's disease: interaction of apolipoprotein $\mathrm{E}$ genotype, family history of dementia, gender, education, ethnicity, and age of onset. Neurology 1996;46:1575-9.

25 Scheltens P, Barkhof F, Valk J, et al. White matter lesion on magnetic resonance imaging in clinically diagnosed Alzheimer's disease. Brain 1992;115:735-48.

26 Brun A, Gustafson L, Englund E. Subcortical pathology of Alzheimer's disease. Adv Neurol 1990;51:73-7.

27 Rich JB, Rasmusson DX, Folstein MF, et al. Non-steroidal anti-inflammatory drugs in Alzheimer's disease. Neurology 1995;45:51-5.

28 Breitner JC, Gau BA, Welsh KA, et al. Inverse association of anti-inflammatory treatments and Alzheimer's disease: initial results of a co-twin control study. Neurology 1994;44: $227-32$.

29 McGeer PL, Schulzer M, McGeer EG. Arthritis and anti-inflammatory agents as possible protective factors for Alzheimer's disease: a review of 17 epidemiologic studies. Neurology 1996;47:425-32.

30 Helmes E, Merskey H, Fox H, et al. Patterns of deterioration in senile dementia of the Alzheimer type. Arch Neurol 1995; 52:306-10.

31 Helmes E, Merskey H, Hachinski VC, et al. An examination of psychometric properties of the extended scale for dementia in three different populations. Alzheimer Dis Assoc Disord 1992;6:236-46.
32 Lau C, Wands K, Merskey H, et al. Sensitivity and specificity of the extended scale for dementia. Arch Neurol 1988;45: $849-52$.

33 Hersch EL. Development and application of the extended scale for dementia. F Am Geriatr Soc 1979;27:348-54.

34 Mirra SS, Heyman A, McKeel D, et al. The consortium to establish a registry for Alzheimer's disease (CERAD). Part
II. Standardization of the neuropathologic assessment of Alzheimer's disease. Neurology 1991;41:479-86.

35 Gearing M, Mirra SS, Hedreen JC, et al. The consortium to establish a registry for Alzheimer's disease (CERAD). Part $\mathrm{X}$. Neuropathology confirmation of the clinical diagnosis of Alzheimer's disease. Neurology 1995;45:461-6.

36 American Psychiatric Association. Diagnostic and statistical manual of mental disorders, $3 r d$ ed revised. Washington, DC: APA, 1980.

37 McKhann G, Drachman D, Folstein M, et al. Clinical diagnosis of Alzheimer's disease: report of the NINCDSADRDA Work Group under the auspices of Department of Health and Human Services Task Force on Alzheimer's Disease. Neurology 1984;34:939-44.

38 Zigmond AS, Snaith RP. The hospital anxiety and depression scale. Acta Psychiatr Scand 1983;67:361-70.

99 Hachinski VC, Potter P, Merskey H. Leuko-araiosis. Arch Neurol 1987;44:21-3.

40 Chimowitz MI, Awad IA, Furlan AJ. Periventricular lesions on MRI. Facts and theories. Stroke 1989;20:963-7.

41 Kobari M, Meyer JS, Ichijo M. Leuko-araiosis, cerebral atrophy, and cerebral perfusion in normal aging. Arch Neurol 1990;47:161-5.

42 Skoog I, Palmertz B, Andreasson L-A. The prevalence of white matter lesions on computed tomography of the brain in demented and non-demented 85 year olds. 7 Geriatr Psychiatry Neurol 1994;7:169-75.

43 Wade JPH, Mirsen T, Hachinski VC, et al. The clinical diagnosis of Alzheimer's disease. Arch Neurol 1987;44:24-9.

44 Ortof E, Crystal HA. Rate of progression of Alzheimer's disease. f Am Geriatr Soc 1989;37:511-14.

45 Stern RG, Mohs RC, Davidson M, et al. A longitudinal study of Alzheimer's disease: measurement, rate, and predictors of cognitive deterioration. Am ₹ Psychiatry 1994; 151:390-6.

46 Berg L, Miller JP, Storandt M, et al. Mild senile dementia of the Alzheimer type: 2. Longitudinal assessment. Ann Neurol 1988;23:477-84

47 Hier DB, Warach JD, Gorelick PB, et al. Predictors of survival in clinically diagnosed Alzheimer's disease and multi-infarct dementia. Arch Neurol 1989;46:1213-16.

48 Brooks JO, Kraemer HC, Tanke ED, et al. The methodology of studying decline in Alzheimer's disease. $7 \mathrm{Am}$ Geriatr Soc 1993;41:623-8.

49 Haupt M, Pollmann S, Kurz A. Symptom progression in Alzheimer's disease: relation to onset age and familial aggregation. Results of a longitudinal study. Acta Neurol Scand 1993;88:349-53.

50 Stern RG, Mohs RC, Bierer LM, et al. Deterioration on the Blessed test in Alzheimer's disease: longitudinal data and their implications for clinical trials and identification of their implications for clinical trials and
subtypes. Psychiatry Res 1992;42:101-10.

51 Boller F, Becker JT, Holland AL, et al. Predictors of decline in Alzheimer's disease. Cortex 1991;27:9-17.

52 Burns A, Jacoby R, Levy R. Progression of cognitive impairment in Alzheimer's disease. F Am Geriatr Soc 1991;39:3945

53 Kramer Ginsberg E, Mohs RC, Aryan M, et al. Clinical predictors of course for Alzheimer patients in a longitudinal study: a preliminary report. Psychopharmacol Bull 1988;24: $458-62$.

54 Katzman R, Brown T, Thal LJ, et al. Comparison of rate of annual change of mental status score in four independent studies of patients with Alzheimer's disease. Ann Neurol 1988;24:384-9.

55 Duara R, Lopez Alberola RF, Barker WW, et al. A comparison of familial and sporadic Alzheimer's disease. Neurology 1993;43:1377-84.

56 Koss E, Edland S, Fillenbaum G, et al. Clinical and neuropsychological differences between patients with earlier and later onset of Alzheimer's disease: a CERAD analysis, Part XII. Neurology 1996;46:136-41.

57 Jacobs D, Sano M, Marder K, et al. Age of onset of Alzheimer's disease: relation to pattern of cognitive dysfunction and rate of decline. Neurology 1994;44:1215-20.

58 Huff FJ, Growdon JH, Corkin S, et al. Age at onset and rate of progression of Alzheimer's disease. $\mathcal{F} \mathrm{Am}$ Geriatr Soc 1987;35:27-30.

59 Morris JC, Edland S, Clark C, et al. The consortium to establish a registry for Alzheimer's disease (CERAD). Part IV. Rates of cognitive change in the longitudinal assessment of probable Alzheimer's disease. Neurology 1993;43:245765

60 Stern Y, Alexander GE, Prohovnik I, et al. Inverse relationship between education and parietotemporal perfusion

61 Stern Y, Alexander GE, Prohovnik I, et al. Relationship between lifetime occupation and parietal flow: implications for a reserve against Alzheimer's disease pathology. Neurology 1995;45:55-60.

62 McLeod JD, Kessler RC, Landis KR. Speed of recovery from major depressive episodes in a community sample of married men and women. F Abnorm Psychol 1992;101:27786

63 Hawkins WE, Duncan DF, McDermott RJ. A health assessment of older Americans: some multidimensional measures. Prev Med 1988;17:344-56. 